


\title{
O NÚCLEO DE ANTROPOLOGIA DO DIREITO, NADIR, E SEU V ENCONTRO NACIONAL DE ANTROPOLOGIA DO DIREITO, V ENADIR
}

\author{
l1111111111111111111111111111111111111111111111111111111111111
}

O NADIR foi assim nomeado tanto em função das letras iniciais das palavras Núcleo de Antropologia do Direito quanto porque nadir é um termo polissêmico e presente em várias línguas ${ }^{1}$. Isso bem retrata a razão de ser desse grupo, sediado no Departamento de Antropologia da Universidade de São Paulo (DA-USP), e que completou 10 anos em 14 de março de 2018, pois seu propósito é explorar e (re)inventar perspectivas entre a antropologia e o direito ${ }^{2}$.

Ao longo dessa década, o grupo manteve reuniões quinzenais para discutir textos de interesse comum, produções de convidados(as), projetos e pesquisas de seus próprios membros (tais como iniciações científicas, dissertações de mestrado, teses de doutorado, de livre-docência, artigos, resenhas, papers para congressos) e trabalhos realizados na interface com a sociedade civil organizada.

Desde agosto de 2009, já fortalecido com a presença não só de estudantes e profissionais da antropologia, mas também do direito, tanto da USP quanto de outras instituições de ensino superior, o grupo vem promovendo, a cada dois anos, o Encontro Nacional de Antropologia do Direito, ENADIR. A programação das cinco edições já realizadas está on line, inclusive alguns dossiês delas resultantes, contendo textos originalmente apresentados em conferências, mesas redondas e grupos de trabalho $(\mathrm{GTS})^{3}$. Considerando o alcance realmente nacional desses encontros, entendemos que eles podem ser considerados balanços

1 Além de ser um nome próprio comum de dois gêneros, nadir, na astronomia, designa o oposto ao zênite: tudo o que está abaixo dos pés de um observador do cosmos e que, embora ele não possa observar, existe. Em hebraico e em árabe nadir significa "raro".

2 Uma apresentação detalhada do NADIR pode ser acessada em http://enadir-2017.blogspot.com/p/nadir_16.html e também em http://dgp.cnpq.br/dgp/espelhogrupo/5911329942852747

3 Ver todos os links em http://enadir-2017.blogspot.com/p/apresentacao_17.html bianuais do estado da arte das pesquisas no campo antropologia do direito brasileira.

Graças às interlocuções entre pesquisadoras(es) do NADIR e da Rede de Estudos Empíricos em Direito, seja por ocasião dos ENADIR e/ou dos Encontros de Pesquisa Empírica em Direito (EPED), ou ainda em função de parcerias em bancas de concursos e de defesas de mestrados e doutorados, surgiu a ideia de a Revista de Estudos Empíricos em Direito abrigar os papers que se destacaram no V ENADIR (2017). A pedido da comissão organizadora dessa edição do Encontro, cada dupla de coordenadores(as) de GTs indicou um paper que especialmente retratasse a sua temática e estabelecesse bons diálogos com a literatura pertinente, além de apontar caminhos metodológicos inovadores.

Neste número da Revista de Estudos Empíricos em Direito, portanto, os(as) leitores(as) encontrarão 12 textos: um de cada GTs do V ENADIR. Eles são versões revisadas de papers apresentados nesses grupos, os quais, por sua vez, sinalizam 12 distintas frentes de pesquisa da antropologia do direito brasileira.

Os(as) autores(as) e suas filiações institucionais também retratam uma diversidade que privilegiamos tanto no NADIR quanto nas edições do ENADIR, de modo que há desde papers de autoria de estudantes de graduação ou recém graduados(as) até trabalhos de docentes, doutores e pós-doutores, todos selecionados em função de seus potenciais teóricos e metodológicos.

Um primeiro bloco de quatro textos retrata a importante presença, na antropologia do direito brasileira, de temas referentes ao sistema de justiça criminal.

"Entre direitos, regalias, regras e castigos: sentidos de justiça nas cadeias do Distrito Federal", de Carolina Barreto Lemos, é um trabalho que recupera in- 
terpretações teóricas de Luís Roberto Cardoso de Oliveira, Roberto DaMatta e Kant de Lima, entre outros, para problematizar aspectos do controle disciplinar presentes no cotidiano das cadeias pesquisadas. A autora apresenta um rico material empírico colhido em entrevistas com presos e presas, bem como etnografias em que demonstra uma complexa relação entre regras disciplinares, baseadas em hierarquias e desigualdades, e certas previsões da Lei de Execução Penal, a princípio universais e igualitárias. A autora conclui que os efeitos dessa paradoxal relação podem ser percebidos na permanência de uma cultura punitivista que interpreta os direitos da população encarcerada como privilégios.

De autoria de Mariana dos Santos Vianna e Pedro Heitor Barros Geraldo, o texto "A construção da verdade e a gestão da informação na Central Disque-Denúncia" revisita um tema clássico da antropologia do direito brasileira concernente à presença da cultura inquisitorial que permeia práticas investigativas de nossas instituições policiais, às quais é atribuído o poder de, diante de situações problemáticas, qualificar ou não determinados comportamentos como criminosos. A opção dos autores por realizar uma pesquisa etnográfica no interior de uma instituição não policial, criada para o recebimento de denúncias daquilo que parte da população espontaneamente classifica como crime, permitiu-lhes elaborar um contraponto empírico que contribui para análises sobre relações entre verdade, saber e poder no campo da administração da justiça.

Poliana da Silva Ferreira assina o texto "Olhar, ouvir e escrever nos Júris de policiais militares de São Paulo" no qual apresenta reflexões metodológicas sobre sua pesquisa acerca do tratamento judicial de homicídios dolosos praticados por policiais militares. Reflete especialmente sobre sua incursão em sessões do Tribunal do Júri, destacando percepções sobre a experiência de "estar lá" na condição de advogada e pesquisadora. O artigo exemplifica como a antropologia pode enriquecer pesquisas empíricas, feitas na pós-graduação em direito, por meio do uso de métodos e técnicas consonantes com o campo da antropologia do direito.

Em “Disjunções na aplicação da medida de proteção por acolhimento institucional para adolescentes em conflito com a lei: diálogos multidisciplinares", Chris- topher Rodrigues Anunciação e Mário Luis Villarruel da Silva apresentam notas de uma pesquisa em que observaram a singular experiência de "errância" de crianças e adolescentes, tanto em situação de vulnerabilidade quanto em conflito com a lei que, por diferentes instituições de cuidado e/ou de controle. A narrativa de uma situação social vivida por um dos autores é descrita de modo a explicitar não somente o jogo de tensões entre tais instituições e os discursos de seus profissionais, mas sobretudo seus efeitos problemáticos para a garantia dos direitos fundamentais dessas crianças e adolescentes.

A maneira por meio da qual alguns grupos culturais e étnicos mobilizam direitos em favor da manutenção de seu patrimônio cultural, dentro ou fora dos tribunais, compõe a temática de um segundo bloco que abriga com dois textos.

Em "Direitos Intelectuais Indígenas no Brasil: Instrumentos Jurídicos e Conflitos Ontológicos", Vitor Henrique Pinto Ido examina três diferentes casos de judicialização de conflitos relacionados à violação do direito à propriedade intelectual de povos indígenas e tradicionais, neles identificando fenômenos semelhantes. $\mathrm{O}$ autor enuncia ambivalências decorrentes quando fenômenos pertinentes a povos indígenas e tradicionais são interpretados segundo categorias jurídicas estranhas a eles, advindas de outras concepções do que são direitos, propriedade e mesmo justiça. Com isso, demonstra como usos estratégicos dessas concepções por tais povos, na defesa de seus respectivos patrimônios intelectuais, transitam entre a "indigenização do direito" e o risco da "mercantilização da cultura indígena”.

O texto "Memórias do cativeiro e do jongo no Vale Histórico do Rio Paraíba do Sul -São Paulo", escrito por Diego da Costa Vitorino e Dulce Consuelo Andreatta Whitaker, apresenta as memórias do jongo em Bananal como uma significativa manifestação cultural da região, reconhecida em 2005 como patrimônio imaterial pelo Instituto do Patrimônio Histórico e Artístico Nacional (IPHAN) e pelo Centro Nacional de Folclore e Cultura Popular (CNFCP). Segundo os pesquisadores, essa expressão da cultura imaterial negra atualiza, em seus ritmos e letras, memórias do tempo da escravidão e retrata relações de poder 
e resistências. A pesquisa etnográfica, feita por meio de observações, entrevistas e coleta de história oral, teve como uma de suas conclusões a importância da difusão de práticas tradicionais em escolas públicas e privadas a fim de favorecer a proteção jurídica do patrimônio cultural e imaterial de grupos historicamente vulnerabilizados.

Um terceiro bloco, com mais quatro textos, ilustra novas problemáticas que atualizam o campo de estudos sobre relações de gênero e sistemas de justiça - terreno inaugural das intersecções entre antropologia e direito no Brasil - bem como registra o interesse de estudantes de direito pelo uso de abordagens etnográficas em suas pesquisas.

Beatriz Accioly Lins, no paper "'Não existe privacidade 100\% na internet': sobre leis, mulheres, intimidade e internet", apresenta uma pesquisa sobre debates relativos a projetos de lei pertinentes à "pornografia de vingança" ou "exposição via internet" de imagens e material de conteúdo íntimo. Por meio de densa pesquisa etnográfica realizada com fontes diversas e heterogêneas, como materiais midiáticos, participação em eventos, entrevistas, documentários, listas de e-mails e interação em redes sociais, a autora analisa os tratamentos legislativo e jurídico dados ao assunto, privilegiando debates sobre alterações na Lei Maria da Penha e no Código Penal a fim de coibir a "pornografia de vingança". Ela expõe o estado da arte da discussão e chama a atenção para as principais disputas em jogo.

O texto "Donas de casa, de prostituição: sobre as violências decorrentes da criminalização dos contextos destas práticas", de Letizia Patriarca, apresenta algumas reflexões sobre seu trabalho etnográfico em casas de prostituição de travestis no Jardim Itatinga, em Campinas. Por meio da construção ficcional de uma casa e da relação entre sua proprietária e as travestis que ali moram e trabalham, a autora reconstrói, a partir de frases ouvidas durante seu trabalho de campo, relações, conflitos e situações, delineando um panorama geral das complexas relações de afeto e trabalho desenvolvidas nesses espaços. 0 texto apresenta ainda uma reflexão sobre ética em pesquisa quando interlocutoras são pessoas facilmente identificáveis e que vivem em contextos de ilegalidade.
A temática das relações de gênero também se encontra presente em dois papers que, a nosso ver, indicam a potência de projetos desenvolvidos em faculdades de direito, na interface entre pesquisa, ensino e extensão. Tais textos resultam de pesquisas empíricas, com inspiração etnográfica, feitas por pesquisadoras participantes, respectivamente, da Clínica de Direitos Humanos Luiz Gama (CDHLG) e do Grupo de Empoderamento Feminino (GEF), ambos sediados na Faculdade de Direito da USP.

No primeiro deles, "Clínica de Direitos Humanos Luiz Gama: Reflexões acerca do Direito à Convivência Familiar a partir da pesquisa 'Infância e Maternidades nas Ruas de São Paulo'", Janaína Dantas Germano Gomes, Laura Cavalcanti Salatino e Mariana Nascimento Reyna analisam as percepções de agentes públicos acerca de modelos de família e maternidade orientadores de suas atuações junto à população em situação de rua e, especialmente, mulheres grávidas. Valendo-se de pesquisa qualitativa realizada com informações obtidas junto à Prefeitura Municipal de São Paulo, além de entrevistas e diálogos com atores da rede intersetorial de atendimento a mulheres, gestantes e mães em situação de rua, as pesquisadoras identificam o modo como agentes públicos da saúde e do judiciário interferem no livre exercício dos direitos reprodutivos das mulheres.

Já o segundo texto, “Universidade e Delegacia de Defesa da Mulher: trânsitos e narrativas no enfrentamento à violência de gênero", assinado por 11 pesquisadoras do GEF, apresenta os resultados de observações feitas ao longo de 27 visitas à uma Delegacia de Defesa da Mulher (DDM) na cidade de São Paulo. Elas abordam os principais entraves do expediente do órgão, narrados tanto pelas interlocutoras quanto percebidos pelas pesquisadoras durante a realização do campo. Por fim, as autoras analisam como estereótipos de gênero são mobilizados pelas funcionárias e acabam por delinear a típica vítima de violência doméstica, merecedora da tutela da Lei Maria da Penha.

Os dois últimos textos situam-se em um rico cruzamento em que se encontram a antropologia do direito, da política e do Estado.

O trabalho de Luciana da Silva Sales Ferreira, intitu- 
lado "Produção de documentos e gestão de conflitos: a atuação do Ministério Público na implantação do Projeto Minas-Rio, em Conceição do Mato Dentro/ MG", vale-se de conceitos provenientes da antropologia do Estado para mostrar estratégias utilizadas na elaboração e circulação de documentos em função de um conflito envolvendo direitos humanos e ambientais. Ao fazer tal análise, a autora questiona os limites do que denomina "tecnologias participativas" na defesa dos direitos humanos de populações afetadas por empreendimentos mineradores.

No texto "Tecnologias de governo e migração internacional: pistas para pensar as experiências das crianças em situação de refúgio no Brasil", Fernanda Cruz Rifiotis propõe uma agenda de pesquisa que não se limita apenas a apontar as lacunas deixadas por políticas públicas e legislações brasileiras no que se refere à proteção dessas crianças. Em diálogo com estudos da área da antropologia da infância e propondo contribuir para o desenvolvimento de uma emergente antropologia do sujeito, a pesquisadora convida-nos a atentar para o estudo de práticas criativas por meio das quais crianças podem se afirmar como sujeitos, elaborando novos modelos de existência.

Nós esperamos que as leituras desses doze textos não só contribuam para estreitar os laços já existentes entre pesquisadoras(es) dos campos do direito e da antropologia como estimulem e incrementem novas interlocuções, colaborações e atividades transdisciplinares entre o NADIR e a Rede de Pesquisa Empírica em Direito.

Boa leitura a todas e todos!

\section{ANA LÚCIA PASTORE SCHRITZMEYER ${ }^{4}$, BRUNA ANGOTTI ${ }^{5}$ E CARMEN SILVIA FULLIN ${ }^{6}$}




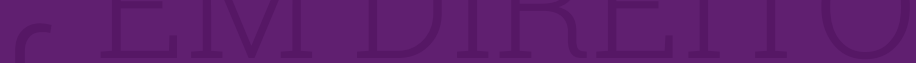

1 Revista de Estudos EMPÍRICOS IES EM DIREITO

EMPIRICAL

Rev

LEGAL STUDIES EN Revista de Estudos BRAZILIAN
Journal of EM DIREITO EMPIRICAL Revista de Estudos

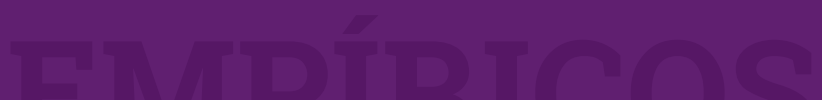
EMPIRICUS EM DIREITO LEGAL STUDIES BRAZILIAN Journal of Revista de Estudos EMPÍRICOS EM DIREITO LEGAL STUDIES BRAZILIAN
Journal of Revista de Estudos Heviola ú woludo EMPIRICOS EM DIREITO EMPIRICAL $\operatorname{Rev}$ Revista de Estudos LEGAL STUDIES Rev EMPIRICOS EM DIREITO BRAZILIAN Journal of EN Revista de Estudos EMPIRICAL Rev FMDIRTC 